\title{
El Humanismo ético del siglo XXI a través del pensamiento de Ryszard Kapuscinski
}

\author{
Fernanda Tusa JumBo \\ Universidad Técnica de Machala, Ecuador \\ ftusa@utmachala.edu.ec
}

Recibido: 21 de junio de 2016

Aceptado: 6 de agosto de 2016

\begin{abstract}
Resumen
El presente trabajo de investigación académica constituye un aporte desde la ciencia de la comunicación social a la formación ética del profesional del Comunicador Social, a partir de un estudio de autor, tomando como referencia al periodista bielorruso Ryszard Kapuscinski y su texto ' 10 reflexiones sobre el periodismo'. En este espacio, intentamos una aproximación teórica al 'concepto de humanismo ético del siglo XXI' tantas veces mencionado por Kapuscinski a lo largo de su obra, a fin de comprender la relación existente entre deontología periodística y valores universales del ser humano. En cuanto a la metodología utilizada, se presenta el análisis de contenido y la revisión bibliográfica y documentada acerca de la ética propuesta por Kapuscinski. Como conclusión se infiere que en el siglo XXI los nuevos valores del ser humano están anticipando desde ya el devenir ético de la humanidad y ante tal contexto, el reto de la academia será profundizar en investigaciones de naturaleza social que impulsen la reflexión y el análisis acerca de autores trascendentales dentro del periodismo y la comunicación como fuera la figura del genio bielorruso.
\end{abstract}

Palabras clave: Kapuscinski; humanismo; ética; comunicación; educación.

\section{The ethical humanism of the XXI century through the thought of Ryszard Kapuscinski}

\begin{abstract}
The present academic research is a contribution since the social communication science to the professional ethics training of the Social Communicator, from a study author, taking as reference the Belarusian journalist, Ryszard Kapuscinski, and his article " 10 reflections about journalism'. In this space, we try a theoretical approach to the global humanism of the twenty-first century concept that Kapuscinski mentioned many times throughout his work, in order to understand the relationship between journalistic ethics and universal human values. About the methodology, this paper uses the content analysis and literature and documented review about the global humanism proposed by Kapuscinski. In conclusion, in the XXI century the new values of human beings are anticipating the ethical future of humanity. In front of this context, the challenge of the academy will deepen research with social nature, which promotes reflection and analysis about transcendental authors in journalism and communication such as the case of the Belarusian genius.
\end{abstract}

Keywords: Kapuscinski; humanism; ethics; communication; education. 


\section{Referencia normalizada}

Tusa Jumbo, F. (2016) El Humanismo ético del siglo XXI a través del pensamiento de Ryszard Kapuscinski. Historia y Comunicación Social. Vol 21, número 2, páginas 363-377.

Sumario: 1. Introducción. 2. Estado de la cuestión. 2.1. Humanismo ético en la obra de Kapuscinski. 2.2. Enseñanzas de Kapuscinski aplicadas a la formación de periodistas. 3. Metodología. 3.1. Resultados y discusiones. 4. Conclusiones. 5. Referencias bibliográficas.

\section{Introducción}

Kapuscinski es considerado el periodista más importante del siglo XX debido a su trayectoria de cincuenta años, su compromiso con el bien común, su identificación plena con la época en la que vivió y además, por reivindicar aquellos continentes y países que fueron olvidados por el primer mundo, acciones que le valieron múltiples reconocimientos y galardones.

Recorrió el mundo, entre aviones, trenes y automóviles, registrando hechos y contando historias y conflictos. En total, visitó 100 países de Europa, África y América Latina, siendo testigo de fenómenos sociales que después describió en sus 21 libros publicados y en los artículos que acogieron medios de renombre como el New York Times, Frankfurter Allgmeine Zeitung, Revista Time, entre otros. Kapuscinski recibió el Premio Príncipe de Asturias de la Comunicación y Humanidades en 2003 y fue declarado Doctor Honoris Causa por varias universidades del mundo.

Su nombre es considerado parte de la historia del periodismo clásico, de aquel oficio vinculado al buen escribir y selecto lenguaje. Se consideraba un periodista independiente y a menudo criticaba a los grandes multimedia, especialmente a aquellos que a su juicio manipulaban la opinión pública o creaban un mundo virtual en menoscabo de la realidad.

Cabe mencionar que el genio bielorruso hizo uso de la narración como una de las características fundamentales de su actividad. Se podría decir que el mayor aporte de Kapuscinski reside en la acuciosidad, la audacia y el olfato del periodista, algo que debe ser permanentemente utilizado, independientemente de la época en que se desenvuelva.

En el mundo del periodismo, Kapuscinski es visto como un eje vital, dinámico, cambiante y transformador, quien le dio un nuevo enfoque al oficio, con un aporte altamente significativo a la profesión, el cual radica justamente en el valor humano. Para el autor, el periodista debe estar inmiscuido en una vocación cuasi de sacerdocio, no solo dedicarse a escribir una noticia porque tiene que cumplir una orden de su jefe inmediato, sino que invita a que el periodista viva y conviva al momento de contar una noticia, que se involucre plena e integralmente. En otras palabras, su reflexión busca que el periodista sea más tolerante, más humano, más equilibrado. 
De todos los medios que analizó, fue muy crítico con la televisión por considerar que a través de la pantalla chica se difundían versiones erróneas sin contraste alguno de fuentes informativas. Para Kapuscinski, la televisión había terminado con la responsabilidad personal que debe tener todo periodista, algo que él consideraba clave en el proceso de construcción de la noticia.

El gran aporte de Kapuscinski, y la importancia de este análisis de autor, está en los conceptos que trasladó del ejercicio práctico a la enseñanza del periodismo, los cuales hablan del compromiso militante, los contextos y el respeto por los demás, puesto que era partidario de encontrar al otro, al prójimo, conocer sus costumbres, lenguajes y modos de vida. Sostenía que coexistir con personas diferentes es lo que genera empatía y cimienta el espíritu del ser humano.

Es así que la presente investigación intentará compendiar la acción de Kapuscinski, desde la perspectiva del humanismo global, porque eso es lo que siempre apreció en el ejercicio de la profesión: el valor del periodista: su nobleza y responsabilidad con la verdad.

\section{Estado de la cuestión}

Garagy (2006) propone cuatro puntos sobre los que debiera darse la formación actual de los estudiantes en las carreras de comunicación: 1) la comunicación exige una preparación específica que debe darse en la universidad, pues se trata de una disciplina con carácter científico, 2) las universidades deben brindar a los nuevos comunicadores un bagaje cultural humanista lo suficientemente amplio para comprender las claves antropológicas del mundo actual, 3) la formación profesional no termina con el grado, pues es una obligación personal y tarea continua de preparación y 4) ser profesional exige en contrapartida ser una buena persona.

Sobre el estudio de Garagy quiero mencionar dos variables que se han citado dentro de su discurso y sobre las cuales se levanta la presente investigación académica y es que el humanismo del siglo XXI que tanto se demanda a la universidad, en el acto de trasmitir una sólida educación en valores, se promueve justamente con la enseñanza de filosofias como las del periodista bielorruso Ryszard Kapuscinski.

En este sentido, el presente artículo de naturaleza descriptiva-exploratoria y propositiva enfoca los aportes de Kapuscinski para entender y entendernos los periodistas como agentes sociales de cambio y transformación en las nociones fundamentales de humanismo y ética en el siglo XXI.

Es importante desarrollar el corpus teórico de este trabajo citando, en un primer punto, el trabajo de Platt (2012) quien caracteriza la visión humanista del periodismo desde un tema recurrente en la producción de Kapuscinski, conocido como la mirada del otro, que no es otra cosa que la capacidad empática del periodista para relacionarse con otras personas. Por lo tanto, su estudio se enfoca en las siguientes ideas: 
- 'El otro' forma parte de una exigencia interior propia para Kapuściński. El acercamiento y entendimiento con sus interlocutores es precisamente el motor que lo impulsa a dar fe de sus realidades y narrar lo que viven.

- La fuente principal en el trabajo periodístico son los otros. El periodismo en sí constituye una recopilación de las voces de estas personas, haciendo que el periodista sea incapaz de trabajar sin la cooperación y el entendimiento mutuo con estos sujetos.

- 'El otro' es, según el periodista bielorruso, un reflejo de nosotros mismos. Construimos nuestras identidades basadas en una identificación que sentimos por lo que no somos. Los otros son un espejo viviente gracias al cual podemos percibir nuestra existencia. El hecho de que en el mundo existen otros seres dinamiza y testimonia, a su vez, nuestro propio existir.

- El individuo no debe sólo intentar lograr un entendimiento mutuo y ponerse al mismo nivel que el otro, sino que es la obligación del hombre ser responsable de éste. Esto representa un reto ético que persigue y moldea la visión kapuścińskiana.

- El trabajo de campo del periodista incluye la técnica de la observación participativa. Dicha metodología sostiene que es solamente a través del contacto directo con el otro, proceso etnográfico a través del cual el investigador llega a conocer, compartir y comprender realmente a su sujeto de estudio.

- Gracias al modelo historiográfico de Herodoto, Kapuscinski logra un reporterismo de indagación directa, con el cual ilustra fenómenos históricos reales, ricos en detalles y cuyos personajes son hombres de carne y hueso, protagonistas y contextos históricos extrapolables a cualquier persona, los cuales constituyen metáforas de la realidad universal de nuestra sociedad contemporánea.

Por su parte, Gómez et al (2007) expresa que Kapuscinski vio que ser periodista requería mucho más que un saber, concibiendo a la profesión como vocación laica para un nuevo milenio, cuasi un sacerdocio, alcanzando el hálito de lo sagrado, a criterio del autor.

En este sentido se van configurando las primeras aproximaciones teóricas de lo que podríamos denominar humanismo del siglo XXI y que constituiría el gran reto de un buen comunicador: saber pensar y reflexionar en tiempos de crisis, tomando como contexto la inmediatez, la sociedad del espectáculo, los imaginarios sociales del miedo y la autocensura no de terceros, sino de uno mismo, por miedo a elevar criterios propios e independientes.

Es así que Gómez et al (2007) define las enseñanzas de Kapuscinski de la siguiente manera:

- El periodista necesita saber mimetizarse; es decir, saber camuflarse, tener bajo perfil, lograr una inserción cuasi-natural con el contexto, adquirir una visión micro de las historias cotidianas y dar importancia de las pequeñas noticias. 
- Es un profesional con un profundo respeto por la gente humilde, su humanidad se construye a través del trato amable y respetuoso con sus semejantes, mantiene un plano de igualdad entre las personas y persigue la posibilidad de reconocernos plenamente como individuos. Aquí, la entrevista es un arte de conversar.

- Un auténtico comunicador desconfía de la verdad oficial y mantiene a raya su independencia, sin dejar de lado la cercanía con la gente común. El poder es visto como una desmesura y forma de corruptibilidad. El periodista busca no extraviarse en los laberintos censurables de los gobernantes de turno.

- El periodista trabaja de forma subjetiva; es decir, su oficio es una labor de alma y pensamiento humano. El periodismo es la ciencia del hombre, una ciencia integradora, cuya materia prima es la gente misma.

- Se exige el estudio a lo largo de la vida, lo que significa una continua preparación profesional que demanda tolerancia intelectual y espíritu abierto. El periodista es un adalid de las ideas renovadoras, un enjuiciador del conocimiento y los comportamientos inamovibles. Éste tiene un papel cuasi subversivo, ya que a partir de la nada puede crear cosas nuevas.

- El verdadero periodista es un humanista, mediador de ideas, hombre de mundo, un ambicioso conocedor de las sociedades. En él, la sociedad antrópica delimita su razón de ser.

- El periodista aspira a ser un baluarte de la honestidad, no debería pensar en enriquecerse, sino en lograr una entrega absoluta con su oficio, lo económico en él es un complemento, no una imperiosa necesidad.

- Adquiere para sí mismo una exigencia personal que conlleva voluntad, decisión y disciplina. El periodismo es un oficio de corazones firmes y de aquellos profesionales convencidos de su papel frente a la sociedad.

- El comunicador busca diluir el interés personal en aras de cumplir una vocación de servicio social.

- Un periodista existe para los demás; el significado de 'yo' se borra en la voz de 'el otro', lo que es un reflejo y esencia de lo que soy como profesional. La vida es traducida como un destino común donde todos somos pasajeros del mismo viaje.

\subsection{Humanismo ético en la obra de Kapuscinski}

El componente de la ética es altamente valioso desde la postura del autor. La ética en el periodismo define la esencia del profesional y lo pone a prueba en el día a día dentro del ejercicio práctico de este oficio. Para Kapuscinski (2005), los periodistas "crean estados de opinión, y, por ende, ideologías; moldean la imagen que la sociedad moderna se forma del mundo contemporáneo. De ahí la enorme responsabilidad que descansa sobre el periodista, sobre el profesional de raza, el periodista nato, vocacional. Aquel que sobre todo precie la verdad y mantenga a raya todo intento de manipulación". 
A criterio del periodista ecuatoriano Rubén Darío Buitrón, Kapuscinski solía hablar de ética sin hablar de ella, solo con su ejemplo, siendo contundente cuando analizaba y criticaba el creciente poder de los grandes medios en el mundo y la tendencia a la frivolización y estelarización de los periodistas. Sintió de cerca las angustias, el dolor y la digna tristeza de los seres humildes pero rebeldes y esperanzados. Por ello, su trilogía de trabajo fue: ver, comprender y contar, la cual aplicó con profundo compromiso y responsabilidad. Asimismo cuando se refería a las virtudes que deben acompañar a un buen reportero simplemente explicaba que los cínicos no sirven para este oficio.

Era así: con una frase, con una palabra, con un contenido esencial, directo y de varios niveles de sentido, derrocaba los viejos mitos y los tabúes más acendrados entre sus colegas. El periodismo no era, para él, un vehículo hacia la fama, la riqueza, la comodidad o el ejercicio de influencia en su beneficio. El periodismo era, simplemente, un compromiso vital con las sociedades, los pueblos, los países y los continentes que no están en la agenda mediática de los grandes centros de poder mundial (Buitrón 2007: 56-59).

Como fuente de consulta directa y en una entrevista realizada al Director de Comunicación de la Universidad Técnica de Machala, Andrés Carvajal, éste menciono que Kapuscinski le dio un nuevo enfoque al oficio periodístico y su aporte es significativo para la profesión.

Le dio un valor humano al oficio, el periodista de ahora debe estar inmiscuido en la labor y no solo escribir una noticia porque tiene que cumplir una orden de su jefe inmediato, sino que invita a que el periodista viva y conviva al momento de contar una noticia, que se involucre, redirecciona el oficio periodístico tomando en cuenta los cambios que se han presentado en la actualidad como es la revolución tecnológica. Invita a que el periodista sea más tolerante, más humano, más equilibrado. Como dice Kapuscinski, la aparición de la tecnología limitó el ejercicio en ciertos periodistas, en su creatividad, pero él señala que esa esencia de recorrer las calles, de estar en los hechos no debe perderse. En un mundo globalizado no podemos estar aislados de los cambios tecnológicos, y sobre todo Kapuscinski le dio una visión global, integral al periodista como profesional (Armijos, 2015:14).

Otro de los entrevistados para este trabajo de investigación constituyó Pavel Medina, periodista de la periferia, al sur del Ecuador, quien considera en el autor:

un periodista de raza que hizo uso de la narración como una de las características fundamentales de su actividad periodística y apreció el olfato que debe tener todo periodista independientemente de la época en que se desenvuelva. El mayor aporte de Kapuscinski reside en la acuciosidad, la audacia, el olfato del periodista, algo que debe ser permanentemente utilizado. Su capacidad de distinguir un hecho que podía producirse le caracterizó siempre (Armijos, 2015:14).

En el tema de la ética, Kapusinski decía que actualmente los periodistas se han vuelto hombres que no piensan. En consecuencia, el autor pide recuperar la misión inicial del periodismo que significa un alto sentido de responsabilidad con la sociedad, en sus palabras significa "hacer del periodismo una manera de vivir, de ver el mundo y de reflexionar sobre él". 
Esta visión en torno a la ética y las enseñanzas del maestro bielorruso aplicadas al proceso de enseñanza-aprendizaje en las carreras de Comunicación Social, no puede estar desvinculada del concepto de la educación cívica del hombre y del ciudadano como protagonista, teniendo en cuenta un sentido de pertenencia y responsabilidad con una comunidad, concepto mencionado desde el modelo filosófico de Adela Cortina, catedrática de la Universidad de Valencia. Para la autora, la obligación de formular, incorporar y trasmitir criterios morales le corresponde a todas las personas que integran una sociedad. Para construir un mundo más humano se debe generar una moral cívica que compartan todos los ciudadanos de una sociedad democrática, moralmente pluralista y que les permite construir su mundo juntos, precisamente por compartir esa base común (Cortina, 1999).

Finalmente, Cortina propone un modelo educativo con características como: autonomía personal, coincidencia de los derechos que deben ser respetados, participación responsable en proyectos de transformación positiva, y el sentimiento de vínculo cívico con los conciudadanos y con cualquier otro ser humano (Cortina, 1999), aspectos que se tomarán en cuenta en la praxis con estudiantes de la carrera de Comunicación Social de la Universidad Técnica de Machala (Ecuador), en base al estudio de textos de Kapusinski.

\subsection{Enseñanzas de Kapuscinski aplicadas a la formación de periodistas}

A través de una rigurosa revisión bibliográfica y documental hemos procedido a seleccionar diferentes contenidos de autores referentes en la investigación de Kapuscinski, sintetizando en el siguiente listado algunas de las enseñanzas del maestro bielorruso en base al estudio de Serraller (2014) y Toro (2007):

- El periodista debe tener capacidad para generar polémica y participar en los debates de su tiempo.

- Se demanda del periodista ser una persona progresista, que mantenga sus ideales alejados de las versiones oficiales y correcciones políticas. Solo así llegará a convertirse en una voz independiente.

- Los comunicadores sociales hoy en día necesitan volver a las raíces de su oficio, hacer del periodismo una forma de vida.

- La misión del periodista es hacer periodismo, lo que significa viajar en un peregrinaje constante con uno mismo, entender las causas profundas del mundo y ser un humanista de reflexiones libres.

- El periodista deber ser un detective del otro y proyectar en los demás una capacidad inquisitiva del ser curioso.

- Todo periodista es un historiador y un traductor del sufrimiento de la humanidad.

- Hay que asumir el periodismo como una profesión para maestros, como una noble vocación a la que se entrega plenamente para toda la vida. 
- El verdadero comunicador tiene que liberar a los géneros periodísticos de su estructuralismo limitado. En este sentido, se podría decir que se debe dar alas al reportaje, elevándolo a la categoría de un arte universal e imperecedero.

- Hay que dignificar la profesión, considerada por muchos como un oficio coyuntural y meramente informativa. Realidad y creatividad tienen que caminar de la mano, haciendo un periodismo mágico, en atención a esa doble dimensión: descriptiva y simbólica.

- El trabajo consiste en recrear mundos, dejar huella en el lector, trascender la actualidad, lograr que el periodismo sea una experiencia intelectual y estética, una obra de arte total.

- La producción periodística debe tener como fin enlazar una reflexión con una acción trepidante.

- Los periodistas deben hacerse a sí mismos, sin esperar que nadie les patrocine ni les enseñe a moverse por el mundo. Ser personas entusiastas, afrontar y aprovechar retos, atesorar experiencias e ir sumando especialidades, no decir nunca que no.

- La calidad de los textos no es suficiente, también es necesario pensar en los temas que permitan a las sociedades reflejarlas de la manera más fiel y argumentada posible.

- Hay que hacer periodismo narrativo y comprometido. Realizar trabajos que involucren problemas y situaciones de las grandes mayorías de la población. En otras palabras, posicionar el compromiso social.

\section{Metodología}

La presente investigación recurrió al método inductivo a través de la aplicación de las siguientes técnicas:

- Análisis cualitativo de contenido

- Revisión bibliográfica y documental

Además se hizo una exploración de contenidos, conceptos y caracterizaciones en torno a la obra de Kapuscinski mediante la revisión de fuentes oficiales consideradas, en este caso, los textos del propio autor, así como ensayos críticos y artículos científicos de investigadores hispanoamericanos y periodistas en ejercicio de la profesión, tomando como referencia las enseñanzas y lecciones del maestro bielorruso.

La muestra sobre la cual trabajamos es el corpus teórico Diez Reflexiones de Ryszard Kapuscinski sobre el Periodismo. 


\subsection{Resultados y discusiones}

El trabajo propositivo del presente artículo se da mediante el levantamiento de una matriz de información donde, a través del análisis cualitativo de contenido, se decodifica el texto Diez Reflexiones de Ryszard Kapuscinski sobre el Periodismo bajo las variables:

- mensaje,

- valores inscritos y

- aplicación de los mensajes de Kapuscinski al ejercicio práctico en el aula

El objetivo de este trabajo es extrapolar los mensajes y valores contenidos en el texto, objeto de estudio, y trabajar con futuros profesionales del periodismo, desde las aulas universitarias. Fue así que el proceso experimental de la investigación de caso se dio con estudiantes de segundo, cuarto y quinto semestre de la carrera de Comunicación Social de la Universidad Técnica de Machala, ubicada al sur del Ecuador, en un período que comprende los años 2014-2016.

Con los jóvenes universitarios dedicamos varias horas de clase al análisis reflexivo y crítico de las lecciones de Kapuscinski donde, a través de ejercicios direccionados por el docente y la participación activa del estudiante, se contextualizó la aplicación práctica de las reflexiones contenidas en dicho leccionario. La tabla resultado se expone a continuación:

Tabla 1. Matriz de análisis del texto 'Diez Reflexiones de Ryszard Kapuscinski sobre el Periodismo'

\begin{tabular}{|c|c|c|}
\hline Mensaje del autor & $\begin{array}{c}\text { Valores inscritos en el } \\
\text { mensaje }\end{array}$ & $\begin{array}{c}\text { Aplicación a ejercicios prácticos } \\
\text { en el aula con estudiantes } \\
\text { universitarios de la carrera de } \\
\text { Comunicación Social }\end{array}$ \\
\hline $\begin{array}{l}\text { Heródoto era un } \\
\text { hombre curioso que } \\
\text { se hacía muchas } \\
\text { preguntas, por eso } \\
\text { viajó por el mundo de } \\
\text { su época en busca de } \\
\text { respuestas. }\end{array}$ & $\begin{array}{l}\text { - tener curiosidad, hacer } \\
\text { preguntas } \\
\text { - saber contextualizar las } \\
\text { informaciones } \\
\text { - buscar respuestas y } \\
\text { contextos }\end{array}$ & $\begin{array}{l}\text { Desarrollar la curiosidad del } \\
\text { estudiante con la observación } \\
\text { in situ de noticias dentro de los } \\
\text { predios universitarios, valorando } \\
\text { los enfoques, las perspectivas y } \\
\text { la apertura de visiones de campo } \\
\text { (flexibilidad paradigmática) }\end{array}$ \\
\hline $\begin{array}{l}\text { Los buenos reporteros } \\
\text { son buscadores de } \\
\text { contextos, de las } \\
\text { causas que explican } \\
\text { lo que sucede. Sin } \\
\text { embargo, el periodismo } \\
\text { de la actualidad está } \\
\text { interesado en las } \\
\text { pequeñas noticias sin } \\
\text { contexto. }\end{array}$ & $\begin{array}{l}\text { - adoptar un espíritu } \\
\text { viajero, desarrollar } \\
\text { pasión y vocación por la } \\
\text { corresponsalía de viajes } \\
\text { - encontrar causas que } \\
\text { expliquen lo que sucede en } \\
\text { su contexto inmediato y } \\
\text { mediato de vida }\end{array}$ & $\begin{array}{l}\text { Trabajar en una mesa-debate } \\
\text { sobre las problemáticas } \\
\text { coyunturales del Estado Nación, } \\
\text { con el fin de que el estudiante } \\
\text { sepa contextualizar, encontrar } \\
\text { causas y dar respuestas a los } \\
\text { problemas socio-económicos } \\
\text { que vive la población de un } \\
\text { determinado país }\end{array}$ \\
\hline
\end{tabular}




\begin{tabular}{|c|c|c|}
\hline Mensaje del autor & $\begin{array}{c}\text { Valores inscritos en el } \\
\text { mensaje }\end{array}$ & $\begin{array}{l}\text { Aplicación a ejercicios prácticos } \\
\text { en el aula con estudiantes } \\
\text { universitarios de la carrera de } \\
\text { Comunicación Social }\end{array}$ \\
\hline $\begin{array}{l}\text { El periodista del siglo } \\
\text { XXI se diferencia del } \\
\text { periodista del siglo } \\
\text { XX en el sentido } \\
\text { técnico. Antes se tenía } \\
\text { libertad para moverse, } \\
\text { se dependía mucho } \\
\text { del talento y la validez } \\
\text { personal (en un lugar el } \\
\text { periodista sabía lo que } \\
\text { veía). Hoy el periodista } \\
\text { no cumple a cabalidad } \\
\text { sus investigaciones. }\end{array}$ & $\begin{array}{l}\text { - libertad para moverse en } \\
\text { el ejercicio pleno de la } \\
\text { profesión } \\
\text { - talento innato, habilidades, } \\
\text { capacidades, competencias } \\
\text { profesionales } \\
\text { - validez personal, } \\
\text { autonomía, } \\
\text { empoderamiento del ser } \\
\text { periodista } \\
\text { - direccionamiento propio, } \\
\text { encauzamiento } \\
\text { - oficio técnico, destrezas } \\
\text { manuales y artesanales }\end{array}$ & $\begin{array}{l}\text { - Asignar al estudiante la } \\
\text { realización de un programa de } \\
\text { investigación en su comunidad, } \\
\text { barrial o sectorial, donde ellos } \\
\text { tengan la libertad de moverse en } \\
\text { un terreno conocido y con fuentes } \\
\text { cercanas de información } \\
\text { - Pedir al estudiante que desarrolle } \\
\text { una investigación de naturaleza } \\
\text { social en formato de reportaje } \\
\text { donde se aplique el diario de } \\
\text { campo sin el uso auxiliar de } \\
\text { tecnologías y con la técnica } \\
\text { ancestral de la oralidad, la } \\
\text { escritura y el saber escuchar }\end{array}$ \\
\hline $\begin{array}{l}\text { Los lectores del siglo } \\
\text { XXI deben comprender } \\
\text { el nacimiento del } \\
\text { tercer Mundo, la } \\
\text { llegada al poder y la } \\
\text { soberanía de sociedades } \\
\text { míseras, rurales e } \\
\text { iletradas, un fenómeno } \\
\text { sin precedentes } \\
\text { que cambiará sus } \\
\text { mentalidades y modos } \\
\text { de vivir. }\end{array}$ & $\begin{array}{l}\text { - lectura profunda y } \\
\text { comprensiva } \\
\text { - análisis histórico y } \\
\text { geopolítico de las naciones } \\
\text { - comprensión de la realidad, } \\
\text { ver más allá de los hechos } \\
\text { - interpretación de las } \\
\text { informaciones y noticias } \\
\text { - cuestionamiento, dudar de } \\
\text { la realidad mediática de los } \\
\text { medios como empresa } \\
\text { - aprendizaje contextuado, } \\
\text { ubicado en un tiempo- } \\
\text { espacio determinado }\end{array}$ & $\begin{array}{l}\text { - Desarrollar una línea de tiempo } \\
\text { donde el docente se dé el } \\
\text { espacio de explicar los sucesos } \\
\text { universales más trascendentales } \\
\text { de la historia de la humanidad, } \\
\text { con el objetivo de educar para } \\
\text { pensar } \\
\text { - Sensibiliza al estudiante sobre } \\
\text { los gobiernos y dictaduras de } \\
\text { Latinoamérica y las posiciones } \\
\text { políticas e ideológicas que han } \\
\text { sucedido de forma cronológica } \\
\text { en nuestro territorio, las cuales } \\
\text { forman parte de nuestra cultura, } \\
\text { idiosincrasia e identidad }\end{array}$ \\
\hline
\end{tabular}




\begin{tabular}{|c|c|c|}
\hline Mensaje del autor & $\begin{array}{c}\text { Valores inscritos en el } \\
\text { mensaje }\end{array}$ & $\begin{array}{l}\text { Aplicación a ejercicios prácticos } \\
\text { en el aula con estudiantes } \\
\text { universitarios de la carrera de } \\
\text { Comunicación Social }\end{array}$ \\
\hline $\begin{array}{l}\text { La revolución } \\
\text { tecnológica ha } \\
\text { creado una nueva } \\
\text { clase de periodistas, } \\
\text { llamados media } \\
\text { worker. La mayoría } \\
\text { no sabe ni escribir, en } \\
\text { sentido profesional, } \\
\text { claro. Este tipo de } \\
\text { periodistas no tiene } \\
\text { problemas éticos ni } \\
\text { profesionales, ya no se } \\
\text { hace preguntas. Antes } \\
\text { ser periodista era una } \\
\text { manera de vivir, una } \\
\text { profesión para toda la } \\
\text { vida, una razón para } \\
\text { vivir, una identidad. } \\
\text { Ahora no se identifican } \\
\text { con la profesión. }\end{array}$ & $\begin{array}{l}\text { - pasión por el periodismo } \\
\text { - identidad con su profesión } \\
\text { - direccionamiento ético } \\
\text { - ver en su oficio como una } \\
\text { razón para vivir } \\
\text { - amar lo que se hace } \\
\text { - valorar el arte de escribir } \\
\text { - don de hacerse preguntas } \\
\text { - ser fieles a uno mismo } \\
\text { - posicionar a la ética como } \\
\text { una parte invaluable del ser } \\
\text { humano }\end{array}$ & $\begin{array}{l}\text { - Desarrollar campañas de cultura, } \\
\text { cohesión e identidad por la } \\
\text { profesión periodística, con el } \\
\text { objetivo de aumentar el amor } \\
\text { hacia la carrera y el sentido de } \\
\text { pertenencia, mediante la creación } \\
\text { de un himno periodístico, } \\
\text { un decálogo y jornadas de } \\
\text { integración que motiven al } \\
\text { estudiante } \\
\text { - Analizar testimonios } \\
\text { contenidos en laboratorios } \\
\text { éticos y problemas que muchos } \\
\text { periodistas han tenido que } \\
\text { afrontar en el ejercicio práctico } \\
\text { y real de la profesión, interpretar } \\
\text { las respuestas dadas en cada caso } \\
\text { y desarrollar un simulacro en el } \\
\text { aula, donde el tema central sea la } \\
\text { ética periodística }\end{array}$ \\
\hline $\begin{array}{l}\text { El deber de un } \\
\text { periodista es informar, } \\
\text { de manera que ayude } \\
\text { a la humanidad y no } \\
\text { fomentando el odio } \\
\text { o la arrogancia. La } \\
\text { noticia debe servir } \\
\text { para aumentar el } \\
\text { conocimiento del otro, } \\
\text { el respeto del otro. }\end{array}$ & $\begin{array}{l}\text { - aumentar el conocimiento } \\
\text { de 'el otro' } \\
\text { - fomentar valores en la } \\
\text { sociedad } \\
\text { - auspiciar el respeto por los } \\
\text { demás } \\
\text { - informar con } \\
\text { responsabilidad social } \\
\text { - ayudar a la humanidad } \\
\text { con noticias positivas y } \\
\text { transformadoras }\end{array}$ & $\begin{array}{l}\text { - Pedir al estudiante que desarrolle } \\
\text { trabajos de reportería donde se } \\
\text { informe las noticias positivas } \\
\text { invisibilizadas en los medios. Por } \\
\text { ejemplo, noticias comunitarias, } \\
\text { escolares, de colectivos, entre } \\
\text { otros } \\
\text { - Hacer periodismo de la felicidad, } \\
\text { trabajar con estudios de caso de } \\
\text { aquellos héroes-protagonistas } \\
\text { que transforman el mundo } \\
\text { con pequeñas acciones. Hacer } \\
\text { periodismo de la vida cotidiana }\end{array}$ \\
\hline $\begin{array}{l}\text { Esta es una profesión } \\
\text { muy exigente, es un } \\
\text { trabajo que ocupa toda } \\
\text { nuestra vida, no hay } \\
\text { otro modo de } \\
\text { ejercitarlo. }\end{array}$ & $\begin{array}{l}\text { - exigencia del oficio } \\
\text { - disciplina y vocación del } \\
\text { ejercicio profesional } \\
\text { - dedicación exclusiva al } \\
\text { trabajo periodístico }\end{array}$ & $\begin{array}{l}\text { - Hacer un día de periodistas, a } \\
\text { manera de documental biográfico, } \\
\text { ponerse en la piel de recopilar } \\
\text { testimonios de vida, desarrollar } \\
\text { entrevistas en profundidad, hacer } \\
\text { etnografía de la comunicación. } \\
\text { Documentar el trabajo en formato } \\
\text { video, con el fin de mostrar la } \\
\text { exigencia de esta profesión y la } \\
\text { dedicación exhaustiva que exige } \\
\text { la misma }\end{array}$ \\
\hline
\end{tabular}




\begin{tabular}{|c|c|c|}
\hline Mensaje del autor & $\begin{array}{l}\text { Valores inscritos en el } \\
\text { mensaje }\end{array}$ & $\begin{array}{l}\text { Aplicación a ejercicios prácticos } \\
\text { en el aula con estudiantes } \\
\text { universitarios de la carrera de } \\
\text { Comunicación Social }\end{array}$ \\
\hline $\begin{array}{l}\text { En el periodismo la } \\
\text { actualización y el } \\
\text { estudio constantes son } \\
\text { la conditio sine qua } \\
\text { non. Nuestro trabajo } \\
\text { consiste en investigar } \\
\text { y describir el mundo } \\
\text { contemporáneo, } \\
\text { que está en un } \\
\text { cambio continuo, } \\
\text { profundo, dinámico y } \\
\text { revolucionario. Día tras } \\
\text { día, tenemos que estar } \\
\text { pendientes de todo esto } \\
\text { y en condiciones de } \\
\text { prever el futuro. }\end{array}$ & $\begin{array}{l}\text { - estudio permanente } \\
\text { - educar para pensar } \\
\text { - valor de la investigación } \\
\text { periodística } \\
\text { - estar pendiente e } \\
\text { informado de forma } \\
\text { constante } \\
\text { - prever condiciones futuras } \\
\text { de cambio } \\
\text { - aprendizaje a lo largo de } \\
\text { la vida }\end{array}$ & $\begin{array}{l}\text { - Al comenzar el semestre de } \\
\text { estudio, hacer un acuerdo previo } \\
\text { con los estudiantes en torno a } \\
\text { que una de las actividades de } \\
\text { motivación será, por ejemplo, la } \\
\text { lectura de un cuento corto cada } \\
\text { día, así tendremos en un año } 365 \\
\text { cuentos leídos en casa y en el } \\
\text { aula, cuentos en referencia a la } \\
\text { profesión periodística y con un } \\
\text { mensaje de reflexión } \\
\text { - De esta manera, estaríamos } \\
\text { fomentando la actualización y } \\
\text { el estudio, tanto del estudiante } \\
\text { como del docente } \\
\text { - Asistir con estudiantes a espacios } \\
\text { formativos de aprendizaje, } \\
\text { asimismo generar semilleros de } \\
\text { investigación donde se investigue } \\
\text { temas meritorios a convertirse en } \\
\text { formatos de gran reportaje, que } \\
\text { surgen precisamente desde el aula }\end{array}$ \\
\hline $\begin{array}{l}\text { Tener paciencia y } \\
\text { trabajar. No será } \\
\text { nuestro director } \\
\text { quien decida si somos } \\
\text { buenos periodistas, } \\
\text { sino nuestros lectores, } \\
\text { por tanto hay que hacer } \\
\text { trabajos con calidad } \\
\text { para que el lector } \\
\text { empiece a asociarlos } \\
\text { con nuestro nombre. }\end{array}$ & $\begin{array}{l}\text { - valor del lector } \\
\text { - pensar en nuestro público } \\
\text { por sobre los dueños de la } \\
\text { empresa de comunicación } \\
\text { - calidad del producto final } \\
\text { - rigurosidad del trabajo de } \\
\text { reportería } \\
\text { - marcar una identidad } \\
\text { propia en la escritura } \\
\text { periodística } \\
\text { - desarrollar paciencia en } \\
\text { el ejercicio práctico de la } \\
\text { profesión }\end{array}$ & $\begin{array}{l}\text { - Desarrollar el concepto de marca- } \\
\text { autor, pedir al estudiante que } \\
\text { autodefina cómo sería su sello } \\
\text { personal, qué características } \\
\text { tendría, qué potenciaría de sí } \\
\text { mismo } \\
\text { - Junto al estudiante, visualizar a } \\
\text { futuro su proyección como voz } \\
\text { consolidada ya en los medios, } \\
\text { cuál sería su ventaja profesional } \\
\text { frente a otros periodistas } \\
\text { - Estudiar las biografías de los } \\
\text { periodistas a fin de conocer su } \\
\text { trayectoria, consolidación, y } \\
\text { además analizar cómo llegaron } \\
\text { a conquistar una marca personal } \\
\text { dentro del oficio }\end{array}$ \\
\hline
\end{tabular}




\begin{tabular}{|c|c|c|}
\hline Mensaje del autor & $\begin{array}{c}\text { Valores inscritos en el } \\
\text { mensaje }\end{array}$ & $\begin{array}{c}\text { Aplicación a ejercicios prácticos } \\
\text { en el aula con estudiantes } \\
\text { universitarios de la carrera de } \\
\text { Comunicación Social }\end{array}$ \\
\hline $\begin{array}{l}\text { Para ejercer el } \\
\text { periodismo hay que ser } \\
\text { buenos seres humanos. } \\
\text { Si se es una buena } \\
\text { persona se puede } \\
\text { intentar comprender } \\
\text { a los demás, sus } \\
\text { intenciones, fe, } \\
\text { intereses, dificultades, } \\
\text { tragedias. Tener } \\
\text { empatía y compartir de } \\
\text { forma natural y sincera } \\
\text { el destino del otro. }\end{array}$ & $\begin{array}{l}\text { - ser buenos seres humanos } \\
\text { - comprender a los demás } \\
\text { - desarrollar empatía y } \\
\text { simpatía por el otro } \\
\text { - sensibilizarnos con la } \\
\text { tragedia y dificultad del } \\
\text { otro } \\
\text { - ponernos en los zapatos del } \\
\text { lector }\end{array}$ & $\begin{array}{l}\text { - Incluir actividades de } \\
\text { voluntariado, pedirles a los } \\
\text { estudiantes que desarrollen } \\
\text { productos y servicios } \\
\text { comunicacionales que puedan } \\
\text { beneficiar a los sectores más } \\
\text { vulnerables de la sociedad } \\
\text { - Establecer visitas a zonas } \\
\text { invisibilizadas por los medios } \\
\text { comunitarios, hacer trabajos de } \\
\text { reportería sobre el buen vivir y la } \\
\text { dignidad de estos colectivos, dar } \\
\text { valor a los héroes anónimos de } \\
\text { las sociedades rurales }\end{array}$ \\
\hline $\begin{array}{l}\text { La gente sobre la que } \\
\text { vamos a escribir la } \\
\text { conocemos durante un } \\
\text { brevísimo período de su } \\
\text { vida y de la nuestra. Por } \\
\text { tanto, el secreto está } \\
\text { en la cantidad de cosas } \\
\text { que estas personas } \\
\text { son capaces de decirnos } \\
\text { en un tiempo tan breve. } \\
\text { Aprovechemos esos } \\
\text { minutos y evitemos que } \\
\text { transcurran en silencio, } \\
\text { no demos lugar a } \\
\text { una comunicación } \\
\text { insatisfactoria. }\end{array}$ & $\begin{array}{l}\text { - don del diálogo } \\
\text { - capacidad de escuchar } \\
\text { - habilidad de saber hablar } \\
\text { - valor del flujo } \\
\text { comunicacional } \\
\text { - dar importancia al tiempo } \\
\text { y las oportunidades } \\
\text { - aprovechar las } \\
\text { circunstancias } \\
\text { - valor de las casualidades y } \\
\text { el destino }\end{array}$ & $\begin{array}{l}\text { - Crear situaciones problémicas } \\
\text { de la comunicación a través de } \\
\text { obras de teatro en el aula, donde } \\
\text { se expongan los principales } \\
\text { problemas que el periodista } \\
\text { puede afrontar frente a una fuente } \\
\text { información esquiva, evitativa y } \\
\text { silenciosa } \\
\text { - Trabajar en estrategias de } \\
\text { empatía y el método dialógico } \\
\text { - Abrir un debate sobre lo que es } \\
\text { la comunicación satisfactoria y } \\
\text { la comunicación plena, integral y } \\
\text { holística }\end{array}$ \\
\hline
\end{tabular}

Fuente: elaboración propia.

\section{Conclusiones}

Como conclusión general podemos inferir que el aporte del periodista bielorruso Ryszard Kapuscinski se da tanto para los futuros profesionales en Ciencias de la Comunicación como para los periodistas ya en el oficio práctico, puesto que al primer grupo les motiva el estudio acucioso de la figura del maestro bielorruso para que vean en la carrera del periodismo una forma de vida y desarrollen pasión por lo que hacen dentro de su oficio. Por su parte, al segundo grupo les motiva el estudio de Kapuscinski ya que ven en sus palabras un llamado de volver a las raíces de lo que un día fue el periodismo en su esencial social: una vocación de sacerdocio, con real preocupación por la humanidad y con una fuertísima carga ética.

En este sentido, el concepto de humanismo del siglo XXI lo va a constituir básicamente dos premisas incluidas en el texto Diez reflexiones del periodismo del autor, y 
son: ser buena persona y ser ético. Kapuscinski expresa que el buen vivir, integral y holístico, del individuo como agente social, define el paradigma de lo que debería ser un periodista, un ser empático, sensible y preocupado por los demás, voz cuestionadora que busque (tal cual se maneja epistemológicamente desde la teoría crítica de la comunicación) elevarse como gestor de cambios y transformación social.

A modo de cierre, el presente trabajo buscó aplicar los conceptos de Kapuscinski en actividades prácticas con estudiante universitarios, con el objetivo de que los futuros comunicadores sociales vean en el autor un modelo de periodismo a considerar en el ejercicio real de su profesión.

Kapuscinski fue, es y será un referente ético para el periodismo del siglo XXI, sus ideas, ahora más que nunca, están vigentes, pues en una época de cambios, transformaciones, incertidumbres, en sociedades del miedo y del terror, es necesario apostar hacia el humanismo como forma de vida, como vocación de servicio social.

De manera que el aporte de Kapuscinski radica en un principio en el componente teórico- conceptual. Por lo tanto, se recomienda que la investigación bibliográfica, descriptiva y propositiva de este trabajo sirva para abrir nuevos puentes de estudio y temas de análisis sobre la obra de Kapuscinski, su legado y aplicación al periodismo humanista del siglo XXI.

\section{Referencias bibliográficas}

ARMIJOS, L. (2015). El informe del examen complexivo práctico. El aporte de Ryszard Kapuscinski al periodismo del siglo XXI (examen complexivo). UTMACH, Unidad Académica de Ciencias Sociales, Machala: Repositorio Digital UTMACH.

BUITRÓN, R. (2007). Ryszard Kapuscinski o el otro periodismo. 07 agostos 2015, de Revista Chasqui.

CORTINA, A. (1999). Los ciudadanos como protagonistas. Barcelona: Galaxia Gutemberg.

GARAGY, A. (2006). Nuevos retos para la formación de comunicadores. 06 agostos 2015, de Sala de Prensa. Sitio web: http://www.saladeprensa.org/art675.htm

GÓMEZ, A.; GRANADA, P y VERA, W. (2007). El legado de Kapuscinski a los futuros y actuales periodistas. 07 agosto 2015, de Revista Académica e Institucional de la UCPR.

KAPUSCINSKI, R. (2005). En palabras de Ryzard Kapuscinski, de Agenda Cultural, Universidad de Antioquia. Sitio web: https://aprendeenlinea.udea.edu.co/ revistas/index.php/almamater/article/viewFile/18705/16046

KAPUSCINSKI, R. (2011). Los cinco sentidos del periodista. Fondo de Cultura Económica: Colombia.

KAPUSCINSKI, R. (2002). Los cínicos no sirven para este oficio. Anagrama: Barcelona. 
KAPUSCINSKI, R. (2001). El mundo global en cada aldea. 06 agostos 2015, de diario El País. Sitio web: http://elpais.com/diario/2001/01/28/ opinion/980636407850215.html

KAPUSCINSKI. 06 agosto 2015, de Revista Glossa. Sitio web: http://ut.pr/biblioteca/Glossa2/Journal/march2011/La\%20-figura-de-el-otro-en-la-obra-periodistica-de-ryszard.pdf

KAPUSCINSKI. 07 agosto 2015, de Universidad Complutense de Madrid. Sitio web: http://eprints.ucm.es/31100/1/T36180.pdf

LICHFIELD, G. (2015). Medios digitales deben usar la palabra cuando sea importante. 06 agosto 2015, de Diario La Nación. Sitio web: http://www.nacion.com/ tecnologia/web/mediosdigitales-internet-comunicacion_0_1515248586.html

PLATT, S. (2011). La figura de 'el otro' en la obra periodística-literaria de Ryszard. Revista Glossa 2. Vol 6. No. 1.

PLATT, S. (2012). El periodismo collage de Ryzard Kapuscinski. Miguel Hernández Communication Journal. No. 3. Pág. 1-26.

PLATT, S. (2012). La vida, el pensamiento y la obra del escritor y periodista, Ryszard Kapuscinski (1932-2007). La Laguna: Cuadernos Artesanos de Latina.

PLATT, S. (2012). Las sombras de Ryzard Kapuscinski. Actas - IV Congreso Internacional Latina de Comunicación Social. Sitio web: http://www.revistalatinacs. org/12SLCS/2012_actas/129_Platt.pdf

SÁNCHEZ, C. (2006). Reseña de 'Los cinco sentidos del periodista'. Revista Comunicación y Hombre. No. 2. Pág. 135-137.

SERRALLER, A. (2014). ¿Literatura o periodismo? La recepción de la obra de Ryszard Kapuscinski.

TORO, J. (2007). Los periodistas se han vuelto hombres que no piensan. Revista Cuadernos de Información. Vo. 1. No. 20. 